\title{
Male Partner Involvement in Birth Preparedness and Utilization of Antenatal Care Services: A study in the West Mamprusi Municipality of Northern Ghana
}

\author{
Adadow Yidana ${ }^{1, ~ *}$, Shamsu-Deen Ziblim ${ }^{1}$, Benjamin Yamusah ${ }^{2}$ \\ ${ }^{1}$ Department of Community Health and Family Medicine, School of Medicine and Health Science, University for Development Studies, \\ Tamale, Ghana \\ ${ }^{2}$ Department of Public Health, School of Allied Health Sciences, University for Development Studies, Tamale, Ghana
}

Email address:

adadowy@yahoo.com (Adadow Y.), zshamsu72@gmail.com (Shamsu-Deen Z.),yamusahben@yahoo.com (Benjamin Y.)

${ }^{*}$ Corresponding author

\section{To cite this article:}

Adadow Yidana, Shamsu-Deen Ziblim, Benjamin Yamusah. Male Partner Involvement in Birth Preparedness and Utilization of Antenatal Care Services: A study in the West Mamprusi Municipality of Northern Ghana. World Journal of Public Health.

Vol. 3, No. 3, 2018, pp. 69-75. doi: 10.11648/j.wjph.20180303.11

Received: June 5, 2018; Accepted: June 21, 2018; Published: July 16, 2018

\begin{abstract}
Men as partners in patriarchal societies play a very crucial role in pregnancy and childbirth. It has also been noted that male partners play an important role in family planning in Ghana. This notwithstanding, their involvement in maternal health has not been well investigated. This study sought to establish male partners' involvement in antenatal care utilization in West Mamprusi Municipality The study design was cross-sectional involving 351 respondents both male and female in West Mamprusi Municipality. The participants in the study were people aged 18 years and above who had at least a child born within one year prior to the study. Both questionnaire and focus group discussion guide was to gather the data. Results from the study revealed that majority of the participants had visited health facilities for antenatal care. It further showed that of those who visited for antenatal care, majority did not go with their partners. However, knowledge on birth preparedness and danger signs was good. With respect to place of delivery, majority were encouraged to deliver at health facilities. Majority of the participants averred that male partners noninvolvement in delivery is due to the fact that they perceive pregnancy and delivery as women affair. The majority of male partners supported their spouses' maternal care services; they did not involve themselves in birth preparedness and postnatal care. This calls for proper education to encourage male partners to involve themselves in all matters relating to pregnancy and child-birth.
\end{abstract}

Keywords: Male Partner, Utilization, Antenatal Care, Involvement, Postnatal Care

\section{Introduction}

Men as partners and parents have the potential to influence behaviors that are related to maternal health [1]. Becoming pregnant is a natural process and often come with excitement. However, this excitement could end up threatening the life of women because of obstetric related complications [2]. Available statistics show that over half a million maternal related deaths occur globally. Out of this figure, 99\% are from developing countries [3]. In 2013, an estimated 286,000 maternal deaths occurred in developing countries due largely to preventable complications [4]. This worrying situation leads to calls for the provision of pragmatic and appropriate quality health care services that could reduce maternal morbidity and mortality to the barest minimum [5-6]. Reversing the negative trend would also require decision making regarding stepping up the utilization of appropriate health care services. However, getting these policies to work requires the involvement and participation of male partners [7-8]. Research suggests that male partners have the potential to provide substantial practical, financial and emotional support to women and children to deal with barriers to health care services $[9,10,6]$. In highly patriarchal societies, male partners are decision-makers within their respective families and often control behavior regarding the use of maternal health care services [11]. Surprisingly however, pregnancy and childbirth in patriarchal societies is conceptualized as the 
sole preserve of women [12]. It has been observed that the cultural dynamism and legitimization of men's authority in patriarchal societies, if well harnessed, could positively influence the three levels of delays in obstetric emergencies: delay in awareness of emergency, delay in seeking care and delay in access to health care providers [13-14]. To this end, men have been recognized as key actors in maternal health as their seemingly unsupportive attitude could impact negatively on the health of their spouses and children [1516]. In keeping faith with this recognition as a social reality, the WHO since 2001, has put into place a policy that incorporates male partners into reproductive health programs to achieve safe motherhood [17].

Studies conducted in parts of the globe suggest that male partner's involvement in maternal care has improved the use of reproductive health services, birth preparedness and psycho-social well-being for their wives and children [18]. Other researchers averred that participation of male partners in voluntary HIV counselling and testing was found to be positively associated with uptake of HIV transmission prevention interventions [19]. Other researchers on their part have argued that male partner's participation in maternal health has a positive influence on women's uptake of maternal health care services [20-21]. In 2010, out of global maternal deaths of $287,000,56 \%$ were from Sub-Saharan Africa [22]. In a related development, reports suggest that about 303, 000 women died in 2015 as a result of maternal related complications [23]. Of the 303,000 deaths, about 201,000 of them occurred in sub-Saharan Africa. This alarming trend has made maternal mortality one of history's puzzling ongoing tragedies in sub-Saharan Africa, and the second largest cause of mortality after infectious diseases among women of childbearing age [24-25]. As has been indicated, losing a woman before, during and after childbirth is unacceptable and heartbreaking $[2,26]$.

Various interventions put in place has seen as lightly increased skilled delivery rate of $68 \%$, however, there are still rural-urban disparities in the utilization of maternal health services[3]. According to [27], only $54 \%$ of rural women were delivered by skilled attendants compared to $88 \%$ of urban women in 2011. Report also puts Ghana's maternal mortality ratio at 320 per 100,000 live births [28-29]. Research reveals that majority of women in rural Ghana continue to experience worsened maternal health [30]. Although male partners are stakeholders in maternal health, little has been done about the role they play in birth preparedness and maternal health care in the study area. Studies conducted on male partner's involvement in maternal care were either qualitative or descriptive studies, or are restricted to describing characteristics of male partner's involvement [31-34]. This study thus sought to find out the level of male partner's involvement, preparation and utilization of maternal care services in the West Mamprusi Municipality.

\section{Design and Methods}

A cross-sectional study was conducted in West Mamprusi
Municipality between January and July 2016. There are ten administrative regions in Ghana and each region has a number of districts/municipalities/metropolis depending on the size and population density. The West Mamprusi Municipality, the study area, has three sub-municipalities. The sample size was arrived at using the formula by Snedecor and Cochran to arrive at 340 respondents [35]. A multi-stage sampling technique was used in the sampling process. In the first stage, the municipality was zoned into three and ten (10) communities were then selected from each zone to get 30 communities, using a simple random sampling technique. In the second stage, a probability proportional to size technique was used to select respondents from the selected communities. A simple random sampling technique was then used to select households. In each household, a man and a woman with the youngest child were randomly selected for the study. In situations where the household was made of a man and wife, the two were selected for the study. Eligible participants were those aged 18 years and above and women who had at least one child within the past years at the time of interview. Two focus group discussions were organized within the community. There was also eleven (11) health staff selected to augment the responses from the community members. This brought the total sample size to 351 .

\subsection{Data Collection}

The tool for data collection was a both questionnaire and interview guide. The questionnaire items were designed using maternal and newborn health indicators as captured in the Ghana Demographic Health Survey and other relevant academic studies [29]. A focus group interview guide was used to elicit additional information from the focus group discussants and interview guiding questions being used to gather data from the health care staff. The questionnaire and the interview guides were prepared in English and administered by interviewers who very fluent in Mampruli, the local Language. Each interview took about 40 minutes on average. Before the commencement of the data collection, the research assistants were taken through training to enable them to familiarize themselves with the concepts and questions of this study. The questionnaire was also pretested among 20respondents in East Mamprusi Municipality's town of Gambaga to correct all inconsistencies and inappropriate questions.

\subsection{Data Analysis}

Data for the questionnaire was analyzed using the Statistical Package for Social Sciences (SPSS version 20) whereas content analysis was employed to analyze the qualitative data. Descriptive analysis was used to summarize the socio-demographic characteristics and the level of male partner's involvement in antenatal care utilization and preparation towards childbirth.

\subsection{Ethical Consideration}

Permission to conduct the study was sought from the community members and various heads of the healthcare 
facilities. The participants in the research were made to complete an informed consent form after the purpose of the study was explained to them. This was done to avoid respondents being coerced into filling questionnaires that were administered. Finally, in order to protect the integrity of the respondents, they were assured of anonymity and confidentiality of their identities.

\section{Results}

\subsection{Socio-Demographic Characteristics of Respondents}

Results from the study show an equal distribution of male and female respondents. On the part of health care providers,
$63.7 \%$ were male while $36.4 \%$ were females (Table 1 ). With regard to age distribution, $17.7 \%$ were $10-19$ years, $35.6 \%$ were 20 - 29 years, $27.9 \%$ were 30 - 39 years, $15.3 \%$ of them were $40-49$ years, and $3.5 \%$ were $50+$ years. Among the healthcare staff, $18.1 \%$ were between ages 20 and 29 years, $27.3 \%$ each of the staff were between ages 30 and 39 years, 40 to 49 years and $50+$ years respectively. On educational attainment, $65.2 \%$ of the participants had no formal education, $27.4 \%$ had a certificate, $5.6 \%$ had Higher National Diploma/Diploma, and $0.6 \%$ had a first degree, while $0.3 \%$ had masters certificate. On religious affiliation, $62.3 \%$ were Muslims, 25.4\% were Christians, and $12.3 \%$ were believers in indigenous religion.

Table 1. Socio-demographic characteristics of Respondents.

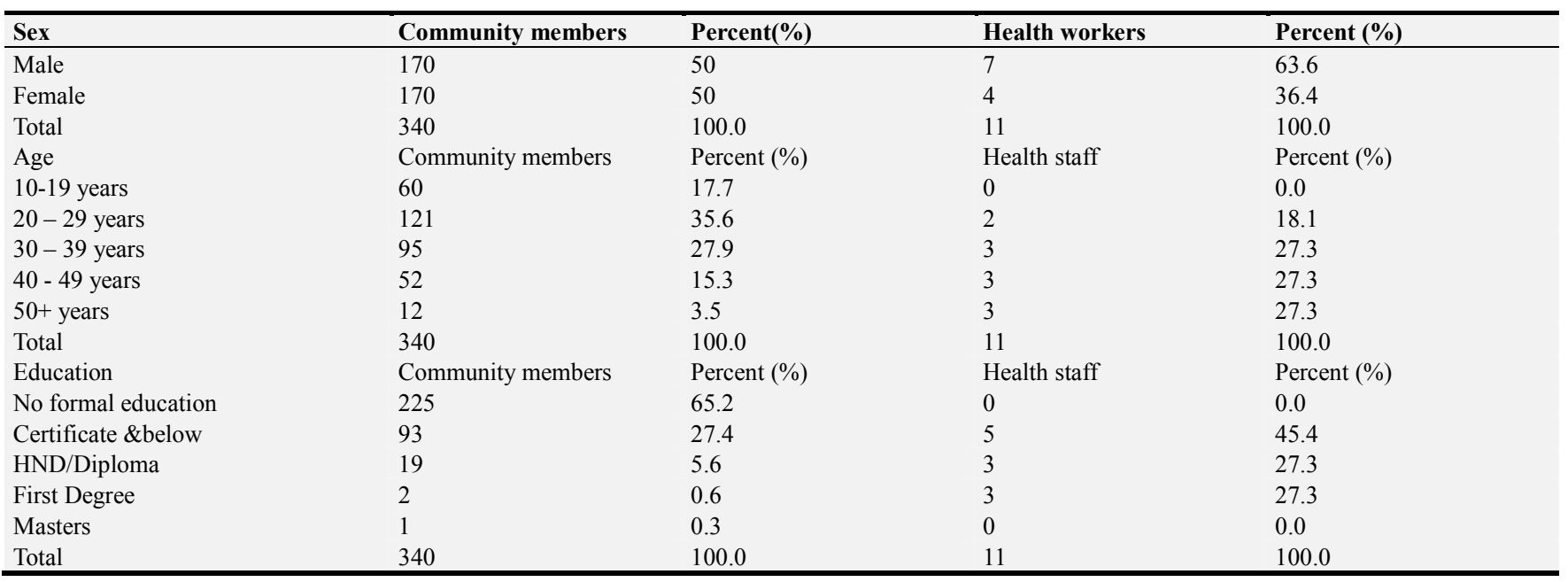

Sources: Field Survey, 2016

\subsection{Uptake of Skilled Delivery}

Data from the study showed that $72.9 \%$ of the respondents visited health facilities for antenatal care during the last pregnancy, while $27.1 \%$ never visited any health facility (Table 2). Interestingly, of the $72.9 \%$ that visited health facilities for antenatal care, $92 \%$ did not go with their spouse. The study also revealed the number of times visits participants made visits to health facilities; $31.9 \%$ had one ANC visit, 19.4\%two ANC visits, $19.8 \%$ had three ANC visits, and $17.3 \%$ had four ANC visits, while $11.7 \%$ had more than four ANC visits.

Table 2. Number of ANC visits by Respondents.

\begin{tabular}{lll}
\hline Number of visits & Frequency & Percent (\%) \\
\hline One time & 79 & 31.9 \\
Two times & 48 & 19.4 \\
Three times & 49 & 19.8 \\
Four times & 43 & 17.3 \\
Above four times & 29 & 11.7 \\
Total & 248 & 100.0 \\
\hline
\end{tabular}

Source: Field Survey, 2016

\subsection{Knowledge of Danger Signs During Pregnancy}

Results showed knowledge of participants on danger signs during pregnancy, childbirth and during postpartum (Table 3). Interestingly, majority (77.4\%) of participant shad knowledge of swollen feet/hand as danger sign during pregnancy, $62.6 \%$ participants had knowledge of retained placenta as danger during child birth, whilst $55.3 \%$ of the participants had knowledge of foul smelling vaginal discharge as danger during postpartum respectively.

Table 3. Knowledge of danger signs during pregnancy.

\begin{tabular}{lll}
\hline Variable & Frequency & Percentage \\
\hline During pregnancy: & & \\
Severe vaginal bleeding & 150 & 44.1 \\
Swollen hand/feet & 265 & 77.4 \\
Vision blurring & 108 & 31.8 \\
During childbirth: & & \\
Severe vaginal bleeding & 190 & 55.9 \\
Retained placenta & 213 & 62.6 \\
Prolonged labor (more than 12 hours) & 130 & 38.2 \\
During postpartum: & & \\
Severe vaginal bleeding & 174 & 51.2 \\
High fever & 167 & 49.1 \\
Foul smelling vaginal discharge & 188 & 55.3 \\
\hline
\end{tabular}

Source: field survey 2016 (multiple responses) $(\mathrm{n}=340)$ 


\subsection{Knowledge of Preparation Towards Childbirth}

The knowledge of preparation put into place towards child birth among the participants reveals interesting responses (Table 4). Regarding knowledge on birth preparedness and complication readiness; majority $(90.6 \%)$ of the participants had knowledge of arranging funds and $50 \%$ had knowledge of identifying possible blood donor. Regarding preparation for birth $\&$ its related complications, majority $(90.6 \%)$ had arranged funds with $98.5 \%$ and $94.1 \%$ preparing essential items for delivery and the food needed respectively. With regard to utilization of the items that participants arranged; $91.8 \%$ utilized arranged fund, 92.6\% utilized arranged transport and 94.1\% utilized items that were arranged for delivery.

Table 4. Knowledge and preparation towards childbirth.

\begin{tabular}{lll}
\hline Variables & Frequency & Percentage \\
\hline Knowledge on birth preparedness and & & \\
complication readiness: & 280 & 82.4 \\
Place of delivery & 308 & 90.6 \\
Arrangement for fund & 299 & 87.9 \\
Arrangement for transport & 230 & 67.6 \\
Arrangement for skilled provider & 170 & 50.0 \\
Arrangement for possible blood donor & & \\
Preparation for childbirth: & 311 & 91.5 \\
Place of delivery & 308 & 90.6 \\
Arrangement for fund & 299 & 87.9 \\
Arrangement for transport & 310 & 91.2 \\
Identified a person to go with for delivery & 335 & 98.5 \\
Prepare essential items for delivery & & \\
\hline
\end{tabular}

\begin{tabular}{lll}
\hline Variables & Frequency & Percentage \\
\hline $\begin{array}{l}\text { Different food items preparation } \\
\text { Utilization of items procured: }\end{array}$ & 320 & 94.1 \\
Utilized arranged fund & 312 & 91.8 \\
Utilized for transport & 315 & 92.6 \\
Utilized a person to go with for delivery & 290 & 85.3 \\
Utilized essential items for delivery & 320 & 94.1 \\
Utilized food items prepared & 322 & 94.7 \\
\hline
\end{tabular}

Source: field survey $2016($ multiple response $)(n=340)$

\subsection{Decision on the Place of Delivery}

From the study, it emerged that $81 \%$ were encouraged by friends to deliver at healthcare institutions, $7.9 \%$ had no suggestion from friends; $7.1 \%$ were discouraged by friends to deliver at health facilities, while $4.0 \%$ of the respondents could not remember the place of delivery advice by friends. On the part of family members, $66.2 \%$ had a discussion with the family about the place of delivery, $33.8 \%$ did not discuss with any family member (figure 1). For those who discussed with family, the following suggestions were given; $81.6 \%$ encouraged them to deliver at the health facility, $11.0 \%$ discouraged them from delivering at the health facility, $4.4 \%$ did not provide any suggestion, while $2.9 \%$ could not remember. The study further considered where spouses gave birth to their current children. Data from the study revealed that $51.9 \%$ gave birth at the hospital, $25.9 \%$ gave birth at the health centre, and $21.1 \%$ gave birth in the house, while $1.1 \%$ gave birth in a private hospital.

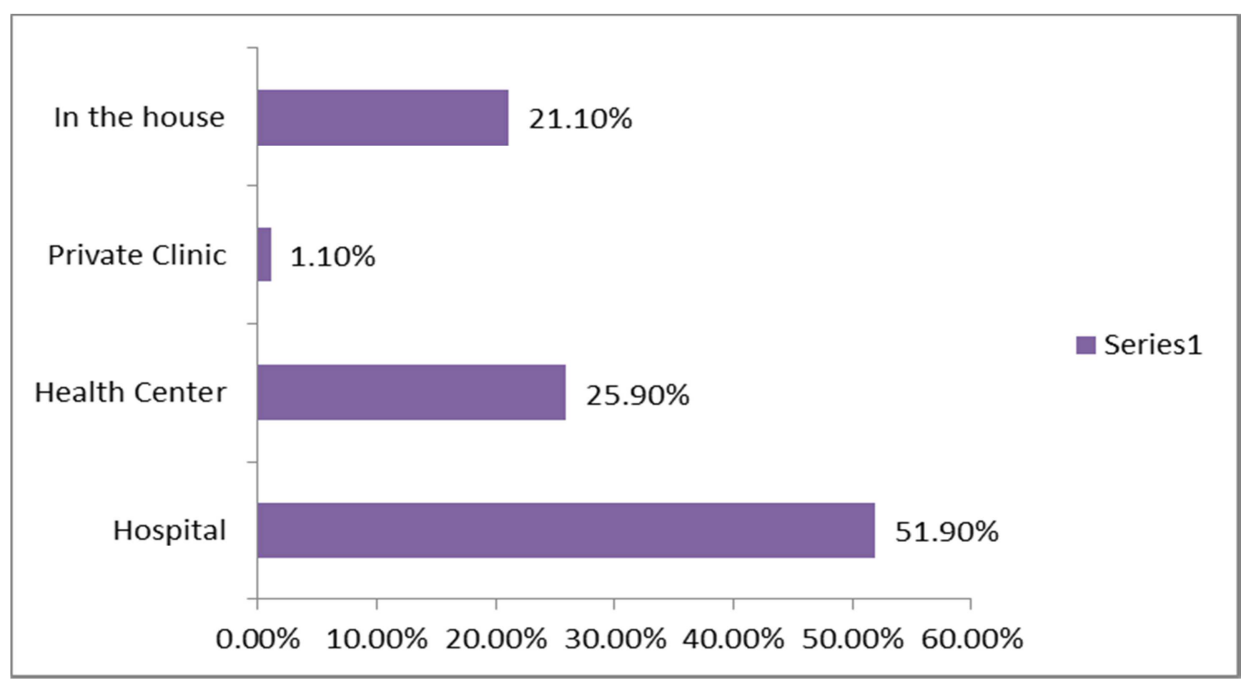

Figure 1. Place of delivery for current child Source: Field Survey, 2016.

Information available on who initiates communication about place of delivery revealed that $40.3 \%$ of the respondents were advised by parents to deliver in a healthcare facility, $34.4 \%$ were advised by family members to deliver in a health care facility, $11.2 \%$ were advised by their husbands to deliver in a health care facility, $7.7 \%$ indicated that it was their mothers who initiated the idea of delivery in a healthcare facility, while $6.5 \%$ were of the view that relatives initiated communication about delivery in the health facility.

\subsection{The Choice of Facility for Delivery}

With regards to the respondents who chose to deliver in a health facility, the following reasons were provided; $32 \%$ were of the view that it was in the interest of the mother to give birth in the health facility, 30\% indicated that it was in the interest of both the husband and the wife to delivered in the health facility, $27.3 \%$ intimated that their decisions were based on previous experience, $3.3 \%$ indicated they were referred by health personnel, and $7.3 \%$ indicated they wanted 
safe delivery of their baby. With regards to the respondents who decided not to deliver their last babies in the health care facilities, they justified their decisions on the following grounds; $65 \%$ based their decision on grounds of uncooperative and harsh attitude of health staff, $10 \%$ indicated that they were not satisfied with the quality of care in the health facilities, another $10 \%$ was afraid of being subjected to caesarian session, $5 \%$ did not have transport to the health facility, another $5 \%$ failed to do so because of previous bad experience, and finally again $5 \%$ of the respondents indicated that during that period they were not having time to send the woman to the health institution for safe delivery. On issues of likability of the nearest health centre, $53.3 \%$ would be attracted by positive attitude of health staff, $18.3 \%$ mentioned opening hours of the health facility as factors that motivates them, $13.6 \%$ considered the distance they covered to access the health facility, $9.5 \%$ considered the services provided by the health facility, $4.1 \%$ looked at cost of service provision as a determinant in the choice of health facility for delivery, and $1.2 \%$ considered the skills of midwives before choosing health facility for safe delivery.

\subsection{Cultural Barriers Preventing Male Partners in Making Delivery Decisions}

Data from the study revealed majority of the participants indicated that there were no cultural barriers that prevent male partners taking decision regarding the place of delivery. However, others were of the view that cultural reasons do prevent male partners from taking decisions regarding the place of delivery. The reasons advanced for not taking decisions were based on the following:

Childbirth is the responsibility of women and does not require men participation in any way. Men only come in if there is a prolonged labor and they have to consult a diviner to get a better understanding (Male participant).

To them, childbirth is a natural phenomenon and does not require much attention from male partners. Some based their arguments on grounds of how society will perceive them.

The idea of attending antenatal clinic with their wives is strange and alien. When a man is seen going to the hospital with his wife, people will see you as a lazy person just following his wife around. Others would say you are being controlled around by your wife (Male participant).

Another participant has this to say:

Men are supposed to stay at home and receive information regarding your wife's pregnancy and birth. You have to stay at home especially during childbirth for the placenta to be brought to you for safe burial.

This is a real depiction of masculinity and show of authority in the traditional sense of the word and the characteristics of men in patriarchal societies. Report from the health care staff reveals the existence of policy initiative aimed at encouraging men to accompany their spouses to antenatal clinics. This initiative according to them is aimed at achieving two things: the first is get husbands to take the voluntary HIV test that is usually conducted for pregnant women and secondly, to get them receive information on critical antennal care issues such as complications during pregnancy. They were quick to concede that this information has not gotten to male partners as they expect it.

\section{Discussion}

There was an equal number of males and females with regards to the community members. However, male staff from the health care providers was $63.7 \%$ while the females were $36.4 \%$. With regard to educational attainment, participants without formal education were $65.2 \%$. It is worth noting that the educational attainment of an individual is directly related to the uptake of skilled delivery. This limited formal education could partly explain why male partners do not consider it necessary to accompany their spouses to receive health care. In the opinion of other experts, mothers with higher educational status are more likely to utilize health delivery service more than those without education [36-38]. With regard to antenatal visits, $31.9 \%$ visited the health care facilities once for antenatal care. The one time visit is due to the fact that some of them visited because of complications experienced at the early stages of the pregnancy. Others did so for want of pregnancy confirmation. Explaining this further, other researchers contend that women who visit health facilities once are less likely to deliver in health facilities than those who visit health facilities more than once [39-40]. Regarding preparation towards delivery, as many as $87.7 \%$ of the respondents indicated they were prepared adequately for delivery. It has also been argued that expectant mothers knowing when they would deliver usually prepare adequately (both clinical and social demands) for delivery of their newborn babies [41].

Data from the study revealed that majority of the respondents gave birth to their current children in the hospital. However as high as $21.1 \%$ of the people still give birth in the house without any health professional's assistance. This finding contradicts other findings that found that institutional delivery was $12.1 \%$ whereas home delivery was $87.9 \%$ [42]. Findings from this study further suggest that family members were key actors' in initiating communication about delivery in health facilities. This corroborates a study which showed that $44.1 \%$ parents took a collective decision on the place of delivery [43]. Some community members based their decision not to deliver at health facilities on cultural grounds. The overall decision is that people in the municipality do not consider cultural issues when taken a decision with regards to place of delivery even though there was a minority decision that was based on culture. The majority decision in this study is not in agreement with studies where it was observed that socio-cultural factors and perceived benefit and need of facility used influence the decision to seek care and also considers how community attitudes influence family decision making [44]. Related studies in Western Uganda found that traditionally, pregnancy is considered as a test of endurance and maternal death if it occurs; although sad, is seen as a normal event [45]. 
Religious denomination was also another issue considered in the study. Data from the study revealed that $62.3 \%$ of the respondents are Muslim. This finding could also be attributed to low skilled delivery in the communities because most of the peoples who are Muslims according to them do not allow their wives to deliver in the hospital or go for antenatal care in any health facility. This finding is in agreement with studies conducted in Ghana which indicated that $66.3 \%$ of mothers who were Muslim faithful and a majority showed a preference for TBA (96\%) [46]. This preference was also indicated by respondents in the focus group discussions. This finding shows a trend that Islamic religious affiliation tends encourages TBA assisted deliveries as compared to the Christian faith. This finding is in agreement with a study conducted in Bangladesh, which concluded that women from other religions had $42 \%$ higher odds of delivering with assistance from SBA's at delivery compared to the women from Muslim religion [47].

\section{Conclusions}

The study revealed that male partners do not accompany their wives to antenatal clinics. They perceive pregnancy and childbirth as solely women affair. However, knowledge on birth preparedness and birth complications is fairly good. To this end, it is worth noting that in highly patriarchal societies, men as heads of households play crucial roles in decision making regarding their spouses access to maternal health facilities and preparation towards delivery. Understanding and appreciating the social dynamics involving male partners influence is important in the negotiation process towards reaching a compromise with the sole aim of improving the health of women.

\section{Conflicts of Interest}

All the authors do not have any possible conflict of interest.

\section{References}

[1] Greene, M. E., Mehta, M., Pulerwitz, j., Wulf, D., Bankote, A., \& Singh, S. Involving men in reproductive health: contribution to development, UN Millennium Project. 2004.

[2] Yidana, A. \& Kuganab-Lem, R. Falling on the Battlefield in the Line of Duty' is not an Option: Knowledge as a Resource for the Prevention of Pregnancy Complication in Rural Ghana; Public Health Research, 2014, 4(4): 120-128 DOI: 10.5923/j.phr.20140404.03

[3] WHO. Maternal death surveillance and response: Technical guidance information for action to prevent maternal death. Geneva, Switzerland: World Health Organization. 2013.

[4] WHO. Women and Health: Today's Evidence, Tomorrow's Agenda. Geneva, Switzerland: World Health Organization. 2018.

[5] Ronsmans, C., \& Graham, W. J. Maternal mortality: who, when, where, and why. Lancet; 2006, 368(9542):1189-200. PMID: 17011946

[6] Story, W. T., Burgard, S. A., Lori, J. R., Taleb, F., Ali, N. A., \& Hoque, D. M. Husbands' involvement in delivery care utilization in rural Bangladesh: A qualitative study; BMC Pregnancy Childbirth; 2012, 12:28. doi: 10.1186/1471-239312-28 PMID: 22494576

[7] Bhatta, D. N. Involvement of males in antenatal care, birth preparedness, exclusive breast feeding and immunizations for children in Kathmandu, Nepal, BMC pregnancy and childbirth; 2013, 13:14. doi: 10.1186/1471-2393-13-14 PMID: 23324410

[8] Kakaire, O., Kaye, D. K., \& Osinde, M. O. Male involvement in birth preparedness and complication readiness for emergency obstetric referrals in rural Uganda. Reproductive health; 2011, 8:12. doi: 10.1186/1742-4755-8-12 PMID: 21548976

[9] Natoli, 1., Holmes, W., Chanlivong, N., Chan, G., \& Toole, M. J. Promoting safer sexual practices among expectant fathers in the Lao People's Democratic Republic, Glob Public Health, 2012, Vol 7(3):299-311

[10] Shefner-Rogers, C. L., \& Sood, S. Involving husbands in safe motherhood effects of the SUAMI SIAGA campaign in Indonesia, J Health Commun, 2004, Vol 9(3): 233-258

[11] Mesane, K., Maputle, S. M., \& Shilubane, H. Male partners' views of involvement in maternal healthcare services at Makhado Municipality clinics, Limpopo Province, South Africa, Afr J. Prm Health Care Fam Med, 2016, Vol 8(2): a929

[12] Carter, M. Husbands and maternal health matters in rural Guatemala: wives' reports on their spouses' involvement in pregnancy and birth. 2002, Soc Sci Med; 55(3):437-50. PMID: 12144151

[13] Barnes-Josiah, D., Myntti, C., \& Augustin, A. The three delays" as a framework for examining maternal mortality in Haiti; Soc Sci Med; 1998, 46(8):981-93. PMID: 9579750

[14] Chavane, L. A., Bailey, P., Loquiha, O., Dgedge, M., Aerts, M., \& Temmerman, M. Maternal death and delays in accessing emergency obstetric care in Mozambique; BMC Pregnancy and Childbirth, 2018, p. 2-18

[15] Kabakyenga, J. K., Ostergren, P. O., Turyakira, E., \& Pettersson, K. O. Influence of birthpreparedness, decision making on location of birth and assistance by skilled birth attendants among women in south-western Uganda. PloS one; 2012, 7(4):e35747. doi: 10.1371/journal.pone.0035747 PMID: 22558214

[16] Aborigo, R. A., Reidpath, D. D., Oduro, A. R., \& Allotey, P. Male involvement in maternal health: perspectives of opinion leaders, BMC Pregnancy and Childbirth, 2018, Vol 18(3): 1-10

[17] Tweheyo, R., Konde-Lule, J., Tumwesigye, N. M., \& Sekandi, J. N. Male partner attendance of skilled antenatal care in peri-urban Gulu district, Northern Uganda. BMC Pregnancy Childbirth; 2010, 10:53. doi: 10.1186/1471-2393-10-53 PMID: 20846369

[18] Mullany, B. C., Becker, S., \& Hindin, M. J. The impact of including husbands in antenatal health education services on maternal health practices in urban Nepal: results from a randomized controlled trial. Health education research; 2007, 22(2):166-76. PMID: 16855015 
[19] Farquhar, C., Kiarie, J. N., Richardson, B. A., Kabura, M. N., John, F. N., Nduati, R. W., et al. Antenatal couple counseling increases uptake of interventions to prevent HIV-1 transmission. J Acquir Immune Defic Syndr; 2004, 37(5):1620-6. PMID: 15577420

[20] Chattopadhyay, A. Men in maternal care: evidence from India; J Biosoc Sci. 2012, 44(2):129-53. doi: $10.1017 /$ S0021932011000502.

[21] Sen, B. K. Women and the law in Burma; Legal Issue on Burma; 2001, 9:28-43.

[22] WHO. Trends in Maternal Mortality: 1990 to 2010. Geneva Switzerland. 2012.

[23] WHO. Global Health Observatory (GHO) datawww.who. int/mediacentre/factsheets/2016, s $348 /$ en/ $^{2}$

[24] Zere, E., Doyin, O., Joses, M. K., Chris, N. M., \& Thomas, M., Inequities in skilled attendance at birth in Namibia: $A$ decomposition analysis, BMC Pregnancy and Childbirth 2011, 11:34 doi: 10.1186/1471-2393-11-34.

[25] Ganle, J. K., Easmon, O., Bernard, O., Anthony, K. E., Augustine, A., \& Richard A. Challenges Women with Disability Face in Accessing and Using Maternal Healthcare Services in Ghana: A Qualitative Study, PLOS ONE 2016, DOI:10.1371/journal.pone.0158361

[26] Ganle, J. K. Ethnic disparities in utilization of maternal healthcare services in Ghana: Evidence from the 2007 Ghana maternal health survey. Ethnicity and Health, 2015, doi: $10.1080 / 13557858.2015 .1015499$

[27] Ghana Statistical Service. Ghana Multiple Indicator Cluster Survey with an Enhanced Malaria Module and Biomarker 2011 Final report. Accra. 2012.

[28] UNICEF. Maternal and Newborn Health Disparities in Ghana, Key Facts. 2016.

[29] GDHS. Ghana Demographic and Health Survey; Ghana Statistical Service and Ministry ofHealth, Ghana. 2014.

[30] Kwapong, O. A. T. F., \& Kwapong, O. The health situation of women in Ghana. Rural and remote health: 2008, 8(963)

[31] Olayemi, O., Bello, F. A., Aimakhu, C. O., Obajimi G. O., \& Adekunle, A. O. Male participation in pregnancy and delivery in Nigeria: a survey of antenatal attendees. J Biosoc Sci; 2009, 41(4):493-503. doi: 10.1017/S0021932009003356 PMID: 19302728

[32] Mangeni, J., Nwangi, A., Mbugua, S., \& Mukthar, V. Male involvement in maternal healthcare as a determinant of utilisation of skilled birth attendants in Kenya. East Afr Med J; 2014, 89(11):372-83.

[33] Ampt, F., Mon, M. M., Than, K. K., Khin, M. M., Agius, P. A., Morgan, C., et al. Correlates of male involvement in maternal and newborn health: a cross-sectional study of men in a peri-urban region of Myanmar. BMC Pregnancy Childbirth; 2015, 15:122. doi: 10.1186/s12884-015-0561-9 PMID: 26013564

[34] Redshaw, M., \& Henderson, J. Fathers' engagement in pregnancy and childbirth: evidence from a national survey. BMC Pregnancy Childbirth; 20013, 13:70. doi: 10.1186/14712393-13-70 PMID: 23514133

[35] Snedecor, G. W., \& Cochran, W. G. Statistical Methods,
Eighthh Edition, Iowa State University Press. 1989.

[36] Adhikari, T., Damodar, S., Saritha, N., Kalyan, B. S., Ravendra, K. S., \& Arvind, P. Factors associated with utilization of antenatal care services among tribal women: A study of selected States; Indian J Med Res. 2016; 144(1): 5866 .

[37] Asundep, N. N., Carson, A. P., Turpin, C. A., Tameru, B., Agidi, A. T., Zhang, K., \& Jolly, P. E. Determinants of access to antenatal care and birth outcomes in Kumasi, Ghana; Journal of Epidemiology and Global Health; 2013, 3, 279288; http://dx.doi.org/10.1016/j.jegh.2013.09.004

[38] Tebekaw, Y., Mashalla, Y. M., \& Thupayagale-Tshweneagae, G. Factors Influencing Women's Preferences for Places to Give Birth in Addis Ababa, Ethiopia; Obstetrics and Gynecology International; 2015, Article ID 439748, 7 pages http://dx.doi.org/10.1155/2015/439748

[39] Belay, A. S. \& Sendo, E. G. Factors determining choice of delivery place among women of child bearing age in Dega Damot District, North West of Ethiopia: a community based cross sectional study, BMC Pregnancy and Childbirth, 2016, DOI 10.1186/s12884-016-1020-y

[40] Ewa, E. E., Lasisi, C. J., Maduka, S. O., Ita, A. E., Ibor, U. W. $\&$ Anjorin, O. A. Perceived Factors Influencing the Choice of Antenatal Care and Delivery Centers Among Childbearing Women in Ibadan North South-Western, Nigeria; Ethiopian Journal of Environmental Studies and Management; 2012, Vol. 5(4): 373-383

[41] August F, Pembe AB, Mpembeni R, Axemo P, Darj, E. Men's Knowledge of Obstetric Danger Signs, Birth Preparedness and Complication Readiness in Rural Tanzania. PLoS ONE 2015, 10(5): e0125978. doi:10.1371/journal.pone.0125978

[42] Alemayehu, M. \& Mekonnen, W. The Prevalence of Skilled Birth Attendant Utilization and its Correlates in North West Ethiopia; Bio Med Research International 2015, Article ID 436938, 8 pages http://dx.doi.org/10.1155/2015/436938

[43] Mahiti, G. R., Dickson, A. M., Angwara, D. K., Columba, K. M., Anna-Karin, H., \& Isabel G. Women's perceptions of antenatal, delivery, and postpartum services in rural Tanzania; Glob Health Action 2015, 8: 28567 http://dx.doi.org/10.3402/gha.v8.28567

[44] Gabrysch, S., Cousens, S., Cox, J., Campbell, O. M. The Influence of Distance and Level of Care on Delivery Place in Rural Zambia: A Study of Linked National Data in a Geographic Information System. PLoS medicine, 2011, 8(1):e1000394. ISSN 1549-1277 DOI: 10.1371/journal.pmed.1000394

[45] Kyomuhendo, G. B. Low use of maternity services in Uganda: impact of women's status, traditional beliefs and limited resources; Reprod Health Matters, 2003, 11(21): 16-26

[46] Lam, Y., Elena, T. B., and Pamela, J. S. Literacy and healthcare-seeking among women with low educational attainment: analysis of cross-sectional data from the 2011 Nepal demographic and health survey; International Journal for Equity in Health; 2013,

http://www.equityhealthj.com/content/12/1/95

[47] Bashar, S. M. A. Determinants of the use of skilled birth attendants at delivery by pregnant women in Bangladesh; Master thesis, Umeå University - Sweden, 2012. 